\title{
A connective ethnography of peer knowledge sharing and diffusion in a tween virtual world
}

\author{
Deborah A. Fields • Yasmin B. Kafai
}

Received: 31 August 2007 / Accepted: 17 November 2008 /

Published online: 10 December 2008

(C) International Society of the Learning Sciences, Inc.; Springer Science + Business Media, LLC 2008

\begin{abstract}
Prior studies have shown how knowledge diffusion occurs in classrooms and structured small groups around assigned tasks yet have not begun to account for widespread knowledge sharing in more native, unstructured group settings found in online games and virtual worlds. In this paper, we describe and analyze how an insider gaming practice spread across a group of tween players ages 9-12 years in an after-school gaming club that simultaneously participated in a virtual world called Whyville.net. In order to understand how this practice proliferated, we followed the club members as they interacted with each other and members of the virtual world at large. Employing connective ethnography to trace the movements in learning and teaching this practice, we coordinated data records from videos, tracking data, field notes, and interviews. We found that club members took advantage of the different spaces, people, and times available to them across Whyville, the club, and even home and classroom spaces. By using an insider gaming practice, namely teleporting, rather than the more traditional individual person as our analytical lens, we were able to examine knowledge sharing and diffusion across the gaming spaces, including events in local small groups as well as encounters in the virtual world. In the discussion, we address methodological issues and design implications of our findings.
\end{abstract}

Keywords Virtual worlds $\cdot$ Knowledge sharing $\cdot$ Knowledge diffusion · Connective ethnography $\cdot$ Peer pedagogy

\section{Introduction}

Researchers interested in learning and collaboration have recently turned their attention to online games and virtual worlds. Following Gee's (2003) observations that many video

D. A. Fields $(\bowtie)$

University of California, Los Angeles, Moore Hall 951521, Los Angeles, CA 90095-1521, USA

e-mail: stareyes@gmail.com

Y. B. Kafai

Graduate School of Education, University of Pennsylvania, 3700 Walnut, Philadelphia, PA 19104-6216, USA

e-mail: kafai@gse.upenn.edu 
games and multiplayer online games provide compelling examples of computer-supported collaborative learning, researchers have begun to examine aspects of this learning such as cross-functional teams (Steinkuehler et al. 2007) or peer-to-peer learning (Nardi et al. 2007). Our research connects to these efforts but moves them into a different context, that of virtual worlds. Virtual worlds share many features of online gaming communities in that they are joined by thousands, if not millions of players; feature dozens, if not hundreds of different spaces; and allow players to create their own avatars (Bainbridge 2007). Unlike online games, activities are more diverse and less structured by built-in goals, and in many virtual worlds, much of their content is player generated. How players manage to navigate these virtual worlds and learn about different norms and practices from others are not wellunderstood processes and are of relevance to researchers interested in collaborative learning at large.

A growing set of studies has tackled the challenge of analyzing knowledge diffusion and sharing in small structured learning communities (Anderson et al. 2001; Barab et al. 2001; Roth 1996; Windschitl 2001). These studies have focused mainly on local classroom communities in which teams of students have engaged in project-based learning. The findings from these studies illustrate that intergroup collaboration in the large classroom community is as important for learning as is the more prominently studied intragroup collaboration within small teams. This paper intends to build on this research by expanding it into the realm of virtual communities that comprise thousands of participants often unknown to players and where players participate in less structured activities. The particular context of our study is a large-scale virtual world called Whyville.net with dozens of different places, games, and activities that at the time of our study featured over 1.5 million registered players ages $9-16$ years. As a focal point, we selected an insider gaming practice, here teleporting, that allowed players to visit secret spaces of a planetary system in Whyville.net. Our goal was to examine the nature of knowledge sharing and diffusion about teleporting in virtual worlds as young players accessed Whyville from within multiple physical contexts of a public club, classroom, or the privacy of their homes.

Documenting, describing, and analyzing the diffusion and sharing of such an insider gaming practice is no small matter given the complexities of movements between online and offline spaces and the large number of participants. We turned to connective ethnography (Leander 2008; Leander and McKim 2003) as a method that would allow us to follow a group of older children or "tween" players as they learned and shared the practice of teleporting across the club, at home, and within the virtual world of Whyville. net. In using a combination of tracking data, video records, field notes, and interviews, we could connect the observations from different times and spaces not accessible simply within the after-school club. These records also included interactions with members of the larger virtual world community. In contrast to previous connective ethnographies (e.g., Jones 2004; Lam 2000; Leander and Lovvorn 2006) that followed individuals into different communities, we used a practice, teleporting, and not an individual as a lens for focusing our analyses in connecting learning across spaces via different data sources.

In the following sections, we will situate our efforts in relation to previous research on knowledge diffusion and sharing within classroom communities as well as the burgeoning body of research of learning in gaming and virtual world communities. In the latter context, we also discuss research that has examined gaming interactions in shared physical spaces such as cybercafés and different approaches to connective ethnography. Our study is based on data collected in the Winter of 2005 when 21 tweens ages 9-12, roughly the same number of girls and boys, voluntarily visited an after-school club about three to four times a week for an hour in the afternoons. Our research questions were: When and where did 
members learn about the insider gaming practice of teleporting? How did club members learn about teleporting? What impacted the sharing and diffusion of teleporting across the club? We gradually widened our research focus from when and where participants gained access to the insider gaming practice, to knowledge sharing between and among peers across multiple spaces, and finally, the knowledge diffusion of the practice in the larger club and virtual world. Our findings illustrate both the need to use multiple analytical lenses in connective ethnography and to understand how the online and offline spaces necessitated shifts in learning strategies for sharing and diffusing the inside gaming practice. The discussion addresses the complexities of understanding and studying peer-to-peer learning in unstructured informal contexts, the methodological challenges and limitations, and considerations for designing situations that capitalize on collaboration in multiple shared spaces.

\section{Background}

The starting point for our research is an increased interest in studying collaboration and learning beyond small structured groups - an area that has received little research attention so far (Cohen and Lotan 1995). This interest is grounded in a shift to understand learning not on an individual plane but as a central aspect of community participation (Lave and Wenger 1991). Some researchers have started talking about communities of learners (Brown and Campione 2004) to distinguish classroom contexts from those of professional practice. A small set of studies has examined how student team members in classroom settings not only interact with each other but also with members of other teams. Most notable here are the research studies of Anderson et al. (2001), Barab et al. (2001), Roth (1996), and Windschitl (2001) that have broken new ground in understanding various facets of collaboration in the larger context of classroom learning communities. For instance, Roth focused on understanding why particular practices were adopted across working teams while others such as the teachers' suggested bracing triangles never crossed into teams' considerations. Both he and Barab et al. examined inter- and intragroup collaboration using Latour's (2005) actor-network theory. Others, such as Windschitl, have focused on establishing a taxonomy of practices that facilitated sharing between teams or identified argument stratagems as in Anderson et al.'s (2001) study that identified comments that elicited and facilitated more expanded conversations.

What we learned from these fine-grained analyses is that collaborative teams do not operate within a vacuum but, in fact, greatly benefit from communicating with members of other teams in the classroom. As Kim et al. (2007) found in a follow-up study of students communicating in cross-class text-based small groups, argument stratagems generated by students spread but not those initiated or modeled by teachers (see also Windschitl 2001). They represent what we have called peer pedagogy (Ching and Kafai 2008), the range of informal collaboration practices available to students. When we studied design teams in a classroom we were able to observe and compare peers with different experiences and how they structured their interactions within and outside of their teams. One of the striking differences between students differing in prior design experience was that those with experience often created richer learning opportunities for inexperienced peers by allowing for failure but providing assistance when needed. Our findings indicated that all students, even those who were inexperienced in design work and, thus, more comparable to students in the previously cited studies, had a wide range of informal collaboration strategies at hand. Still, all of the studies mentioned above took place in classrooms within small groups with structured tasks, at times somewhat open-ended design tasks. 
Unlike the classroom studies, most research on learning in popular games encompasses communities that draw large numbers of participants, often in unstructured groups, yet still require of participants "complex cognitive and cultural knowledge and skills" (Steinkuehler 2006, p. 50). Participating in these communities involves developing one's character (or avatar) with certain skills and conveying a recognized identity within the game, learning strategies of play and socializing with others, and largely relying on in-game or related player discussions and exploration for learning rather than using printed instruction manuals (Gee 2003; Steinkuehler 2006). For instance, Nardi et al. (2007) described what could be called peer pedagogy in analyzing chat to understand how players learned from each other. She found that players learned through spontaneous, contextual conversations "driven by small events" that enabled fact finding, development of tactics or strategies, and working out the moral order of the game (p. 9). Further, in-game identities and socializing is not as "within game" as many perceive it to be. Relationships and talk traverse well beyond the virtual realm in clubs, competitions, and conferences (e.g., Taylor 2006). Some researchers have focused on public cybercafés, analyzing the informal learning and dynamic social interactions present in such spaces (Beavis et al. 2005; Jansz and Martens 2005; Lægran and Stewart 2003; Swalwell 2003). Others have studied the cultural politics of how those spaces are constructed and who is welcomed or restricted from the public spaces (Lin 2008). Indeed, thinking of either physical/offline/real or digital/online/virtual as self-contained denies their flexibility and the ways that people negotiate their performance, meaning, and embodiment within them.

In this study, we focus on the knowledge sharing and diffusion in the combined online and offline spaces of virtual world interactions. With only a few exceptions, previous studies of online and offline gaming have focused on older teenagers or adults, in general, the intended audiences of the most popular massively multiplayer online games (MMOGs) and the general populace of cybercafés. However, children and tweens' increasing activity in popular virtual worlds such as Club Penguin, Neopets, Habbo Hotel, Webkinz, and Whyville has largely been ignored. The paying population of Club Penguin, perhaps the most populous virtual world for young children, was up to 3.5 million in August 2007, not including regular but non-paying members (Barnes 2007), while the registered population of Whyville increased to 3.3 million in April 2008. Yet there are few studies of what children and tweens do on virtual worlds, much less how they learn and teach each other to be a part of these worlds. The exceptions are studies of children's play alone or with a few friends at home (Stevens et al. 2008) or in educational virtual worlds such as Quest Atlantis (Barab et al. 2005), River City (Dede et al. 2004), and Moose Crossing (Bruckman 2000, 2006). However, the educational virtual worlds, or MUVEs (multiuser virtual environments), are so far intended for classroom use and have more structure built into the intended learning activities that generally take place in classrooms. Thus, the dynamics of peer collaboration or play on educational virtual worlds, as opposed to more popular, free-choice virtual worlds, is more limited. Goodwin (2006) argues that there is a general lack of study on children's play and how children socially construct relationships with each other in nonadult supervised spaces. Even more, there is a lack of study on children's online spaces and how they construct social relationships in, and learn to become a part of, these complex social worlds. Our study is situated among two primary spaces of older children's (or tweens') free play, an after-school club and a popular virtual world, and, thus, poses an opportunity to study tweens' learning from each other in informal, generally unstructured, play settings, or "in the wild" (Hutchins 1995).

Research about gaming in either space has provided valuable insights in how player participation in games and virtual worlds is organized. The need to integrate online and 
offline interactions has gathered increasing momentum in the research community, most notably under the umbrella of connective ethnography (Hine 2000; Leander 2008). While the sheer amount of data and detail collected through either ethnography, surveys, or logfiles often suggests a comprehensive coverage, the complexity of gaming spaces (and by extension, of any learning environment) indicates that not any one data source alone but the triangulation of many may do better justice in understanding gaming practices (e.g., Bruckman 2006). Most commercial games or virtual worlds do not lend themselves to large logfile or chat data gathering by independent researchers, and the companies who develop them regard any large database of virtual activities as proprietary information, making such data difficult to access. Our study is an exception to this rule, as the creators of the virtual space of our study, Whyville.net, allowed us access to the entire body of logfile data for participating tweens who gave permission. In this paper, we propose to integrate the data collected of offline and online gaming rather than to examine them as two separate strands. We will present more detail on our particular approach to connective ethnography in the following section.

Thus, the purpose of this study is to capture the knowledge sharing and diffusion across gaming spaces as they are prevalent in tweens' play. Our goal is to expand our understanding of collaboration in large groups within the context of a virtual world and associated access points. It is informed by an understanding that children's introduction to the practices of knowledge sharing and diffusion is often outside of schools, in informal contexts such as virtual worlds. In order to study the everyday unstructured learning of club members, we adapted connective ethnography by narrowing our focus to one insider practice on Whyville, utilizing a massive click-level and chat database as well as more traditional ethnographic data such as field notes, videos, and interviews. By narrowing our focus to a particular practice, we sought to illuminate the complexity of the peer-to-peer knowledge sharing as well as the overall spread of the insider practice across the club over time.

\section{Connective ethnography}

In order to study the tweens' activities in the "multiple, simultaneous space-time contexts" (Leander and McKim 2003) of the club and Whyville, we gathered and analyzed numerous types of qualitative and quantitative data aimed to track the youth in the club over multiple spaces: physically in the club and classroom as well as virtually over multiple spaces on Whyville. Our primary contribution to connective ethnography is our focus on the travel (or diffusion across people) of a practice rather than the movement of several individuals across spaces (e.g., Jones 2004; Lam 2000, 2004; Leander and Lovvorn 2006). In addition, we also developed innovative techniques to make sense of our particular set of data.

\section{Participants \& settings}

Whyville.net is a virtual world with over 1.5 million registered players at the time of the study that encourages youth ages $8-16$ years to play casual science games in order to earn a virtual salary (in "clams"), which youth can then spend on buying and designing parts for their avatars (virtual characters), projectiles to throw at other users, and other goods. The general consensus among Whyvillians (the citizens of the virtual community of Whyville) is that earning a good salary and, thus, procuring a large number of clams to spend on face parts or other goods is essential for fully participating in the Whyville community (Kafai 
and Giang 2008). Social interactions with others are the highlight for most Whyvillians and consist primarily of ymailing (the Whyville version of e-mail) and chatting on the site where users are visible to each other on the screen with their chat in little bubbles above their heads like a cartoon.

Our research involved 21 youth in the fourth to sixth grades (aged 9-12 years) who signed up to play in the virtual world Whyville.net. About a dozen of them were regular players in an after-school club that met for an hour after school 4 days a week from January to March 2005. Most youth were new to Whyville, though one had played for the year before the club started. Six members of the after-school club were sixth graders who also played on Whyville during science class as part of a unit on studying viruses and epidemics (see Kafai et al. 2007). The choices of activities on Whyville during the class were more directed than the open-ended play in the club. In the classes (taught by the same teacher), students were directed by the teacher to engage more in the science activities on Whyville, whereas in the club, members were given no direction on how to spend their time on Whyville. While the primary focus of our analyses is on the members of the after-school club, we could not ignore relationships among class members as a social context of learning in Whyville, as will become apparent in the findings.

The after-school club was set up in a classroom with ten computers. Four computers sat on tables facing away from one long wall, three computers sat on a cluster of tables in one corner away from the long wall, two computers in a side room adjoining the class (the teacher's office), and one computer was alone in another corner. Club members distributed themselves among ten computers, often sharing a computer or wandering around the room talking to others. While the club began as a quiet place, it quickly became loud and lively as participants learned the site and began to shout advice to each other, arrange parties on Whyville, chat, throw virtual projectiles at one another, and critique each other's avatars (Kafai 2008). Club members often dashed from one side of the room to the other (or to the side room) when something interesting was happening on one person's screen or when one club member antagonized another on Whyville. This often led to the tweens' clustering around one computer.

\section{Data}

We collected several kinds of data during the larger study. Ethnographic field notes were recorded daily to capture the overall activity of the club while two video cameras focused on small groups of youth clustered at tables with two to three computers throughout the 9 weeks the club took place in the winter of 2005. Club participants were interviewed individually at the end of the club. In addition, online tracking data including location and chat in Whyville was collected. This tracking/chat data included over 950,000 lines of data for the combined number of 62 children who were members of the club and/or the classes. It recorded every time each child went to a different place in Whyville - in other words every time the screen changed - with a marking of the virtual location and time stamp as well as everything each child typed in public chat or private whisper (private chat from one individual to another in the same virtual location/screen).

Analysis

Our analytical process developed in relation to our research question and though we present it here, it is really part of our findings. Below we describe the main aspects of our analysis, though as it was a process of discovery, the reader should not think that these happened in a 
linear manner. We moved iteratively back and forth between our research questions and different aspects of data analysis, identifying more and more complexity as we pursued the knowledge sharing and diffusion surrounding teleporting (e.g., Charmaz 2000; Glaser and Strauss 1967). One of the first achievements in our analysis was determining a practice to study that allowed us to trace knowledge sharing and diffusion in the club, namely teleporting.

There are two reasons why we chose to study teleporting as a practice. First, it was an insider practice important to socializing on Whyville that could only be learned from another person. At the time of our study, most places in Whyville were easy to access by means of the "Destination Menu" which citizens pull down, scroll through, then click on a specific location (such as the Beach). However, some of the more popular places in which to socialize were not visible to players in the menus available on the site: Earth, Moon, Mars, Jupiter, Saturn, and the Newspaper. Because these sites were not listed in any written records on Whyville, the only way to discover them was from other people. ${ }^{1}$ Therefore, these select places came to represent insider status and many players prized them as social hangouts because they were not overcrowded or overpopulated by newbies (see Fig. 1). Second, because teleporting is accomplished by typing a specific command, "teleport moon" (or "teleport [place]"), each teleport action is visible in the chat records that are part of the logfiles we collected. We can easily search for the occasions when the word "teleport" was typed and find each time a participant teleported. ${ }^{2}$ The choice of teleporting was the first step of analysis after searching and iteratively coding (Charmaz 2000) across the data for peer-to-peer learning and knowledge diffusion.

Once we identified teleporting as a practice to study (a process that involved significant immersion in the data), we conducted three kinds of analyses. First, we searched the logfiles for the first time club members teleported and identified their physical locations based on time stamps and knowledge of attendance and schedules at the club and in the classrooms. Second, using these time stamps as starting points, we pieced together information across all of our data (logfiles, field notes, videos, and interviews) to determine the process and contexts in which each club member learned to teleport. Inevitably there was more information about some individuals than others, but in every case we determined social spatial contexts of knowledge sharing and diffusion. Finally, we inductively and thematically coded incidents of peer-to-peer teaching of teleporting across the data. For the logfiles, this involved identifying times when teleporting was discussed rather than used for transportation (e.g., "how do u teleport" versus "teleport moon") and assembling conversations in the logfiles between school members ${ }^{3}$ before coding them.

Beyond the techniques employed to put together events and learning across multiple kinds of data, two aspects of our approach to connective ethnography are particularly

\footnotetext{
${ }^{1}$ The only exception to this would be learning from an online written record of insider knowledge, namely, an exceptional cheat site where they might be listed as part of "newbie" hints (Fields and Kafai 2007). Based on analysis of the data where we specifically looked for how and whether members used cheats, we are very confident that club members did not learn about teleporting from cheat sites, so it must have been learned from others more directly.

${ }^{2}$ Note that in Whyville as opposed to most massively multiple online games (MMOGs) or chat spaces, there is no window on the screen that keeps a chat record for a particular space. Once something new is typed in a person's chat bubble, or once a person leaves a location (as in the case of teleporting), the chat disappears. Thus, no one on Whyville can actually see a teleport command because the person disappears before the chat would have appeared.

${ }^{3}$ Assembling conversations in logfiles is difficult and time consuming. Because logfiles are listed in order of time stamp and potentially 60 school members could have been logged into Whyville at any given time, we had to filter out those who were in the same virtual space on Whyville and then determine whether they were conversing with each other.
} 


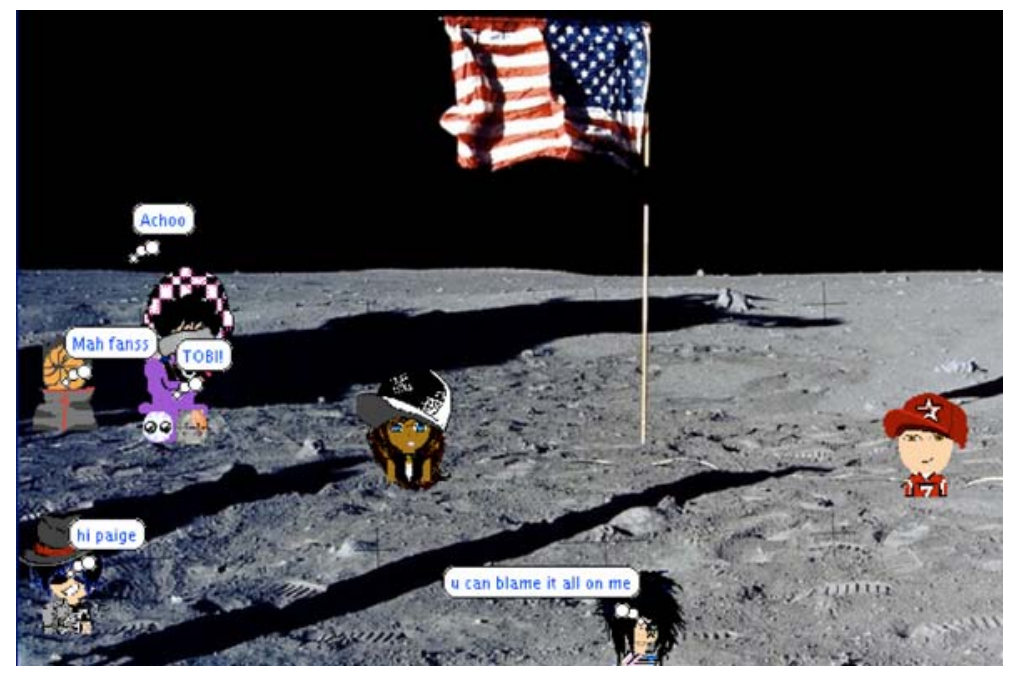

Fig. 1 The moon on Whyville

unique. First, though some have traced individuals by doing a multimodal data analysis (see Leander and Lovvorn 2006, for a particularly detailed analysis of the literacy events across three social spaces in one boy's life), to our knowledge no one has attempted to study learning in a larger group of people (around 20 in the club or classroom space but thousands in the context of the virtual world) interacting across multiple spaces in such a detailed manner. ${ }^{4}$ We accomplished this by narrowing our analysis to the limited practice of teleporting. Second, qualitatively and systematically analyzing logfiles across a group of people rather than using them for quantitative word counts or page hits is also unusual, particularly when one tries to reconcile them with other kinds of data. Bruckman (2000) and Clarke and Dede (2007) have also used logfiles qualitatively to put together incidents that involved the activities of two to four students across multiple spaces, but these analyses were not systematic across a larger group of people. In another example, Nardi et al. (2007) used a tool within the World of Warcraft to gather the chat of all players in a particular game space and analyzed that chat to understand how players learned from each other. Yet this relied on people being in the same virtual space within the game, rather than tracing people or a practice across multiple virtual spaces in the game (much less physical spaces as well). In our analysis we were able to use the practice of teleporting as a marker that traced players' participation across spaces and allowed us to identify how knowledge about this particular practice was shared within the club and larger online community.

\section{Findings}

Like the lens of a camera, we changed the focus of our analysis in increments, gradually widening the lens from individual time points of the observed practice to individual

\footnotetext{
${ }^{4}$ Cf Rodney Jones' work as described in Leander (2008). Jones certainly studied learning across a large group of students, but not in the detailed way that we have-piecing together conversations and events that took place in multiple spaces.
} 
trajectories to trends across club members and whole club events, all centered around learning and teaching the practice of teleporting. In each lens adjustment, different data analyses came into play. In our first close-up on teleporting, the tracking data allowed us to search and find teleport occasions and to determine the first time someone teleported - and from that time to determine where club members were (physically and virtually). Widening the lens a little, we introduced video, field note, and interview data to trace individuals' learning of teleporting, working backward and forward from the earlier identified "firstteleport" time points and studying the contexts in which they learned. Further increasing the area of view, we brought trends among club members into focus, a wider thematic look across our data as a whole - club-wide events that contributed to learning and patterns of talking about teleporting online. Below, we describe each of these aspects of our analysis in turn, gradually zooming out on the insider practice of teleporting as it was learned in the club from time points to individuals to the club as a whole.

Of course, each aspect of our analysis has fuzzy aspects of the others around them. Like a close-up of an insect on a leaf, the whole plant is present and implied in the picture, even if fuzzy and out of focus. Similarly, the data and analysis we present bleed into each other, though we bring certain aspects into focus in the different sections. We will describe how we see this happening throughout the paper and address the benefits as well as limitations in the discussion.

\section{Identifying timing and spaces of the first teleport}

In studying the club, we quickly realized that in order to make sense of sharing and knowledge diffusion, we had to focus on an individual practice. Choosing teleporting, as described above, was a strategic and pragmatic choice-we knew that it was almost surely learned from other people and that we could trace it in chat. As a first step, we did exactly that - identified the first time each club member correctly teleported and where they were at the time - in both Whyville and the world at large (See Table 1).

What Table 1 shows is a simplified map of time points - "first teleports" we might call them - and where the tweens were when they first teleported. There are a few initial things we can see in this close-up focus on first teleports. First, the table maps out the most basic order in which club members first teleported - and that all but one of the club members (named bloofers) did learn to teleport, a finding that should not be dismissed. Second, it begins to take into account the multiple spaces that tweens occupied in the club and Whyville. We can already see from this table that learning to teleport took place in a range of locations and differed between the club members. Indeed, the table points to the need to expand beyond the club and Whyville to take into account both the sixth-grade classes where some club members played on Whyville and implied home space. ${ }^{5}$ Third, there are some obvious clusters and separations between dates, supporting an initial idea that the diffusion of learning to teleport happened in jumps rather than as a continuous stream.

However, when we refocus our research lens to look at individual trajectories of learning, we will see that this table is vastly oversimplified. Learning to teleport did not take place at a single second in time, though it may have been recorded that way in chat data. Further, the word-search capability of tracking data does not even begin to make use of the potential of information embedded in those logs. This identification of time points of

\footnotetext{
${ }^{5}$ While we cannot say for sure that the tweens were at home simply because they were not in class or the club, the opportunities for them to play on Whyville as 9-12 year olds in places outside of school and home are few and far between, based on our knowledge of the activities of youth at the school.
} 
Table 1 First teleports

\begin{tabular}{|c|c|c|c|c|c|}
\hline Username & Name & Date of first teleport & Time of first teleport & Whyville location & Physical location \\
\hline fairi60 & Kaitlyn & Jan 3 & 1:41:32 p.m. & Nutrition Counter & Home \\
\hline whskr29 & Briana & Jan 7 & 1:29:37 p.m. & Whyville Square & Class \\
\hline WOW4 & Gabe & Jan 10 & 8:20:11 a.m. & Leila Patio & Class \\
\hline bluwave & Zoe & Jan 13 & 3:25:41 p.m. & Sector Y & Club \\
\hline sharky404 & Kyle & Jan 14 & 10:44:30 a.m. & Beach & Class \\
\hline masher47 & Aidan & Jan 19 & 11:56:52 a.m. & Warp Tarmac & Class \\
\hline raybeams & Blake & Jan 24 & 7:20:28 p.m. & Bazaar & Home \\
\hline stngray09 & Trevor & Jan 24 & 3:57:33 p.m. & Beach & Club \\
\hline zink & Bryce & Jan 25 & 4:08:34 p.m. & Taxi & Club \\
\hline leo95 & Cole & Jan 28 & 3:45:44 p.m. & Courtyard & Home \\
\hline ivy06 & Isabel & Jan 31 & 4:01:32 p.m. & Beach & Club \\
\hline betelguice & Paolo & Feb 1 & 3:43:18 p.m. & Spin Geek & Club \\
\hline vulcan61 & Brad & Feb 2 & 9:24:44 p.m. & Beach & Home \\
\hline sirius & Scott & Feb 2 & 3:38:06 p.m. & LeilaPatio & Club \\
\hline amarylys & Jill & Feb 3 & 3:30:12 p.m. & Mall Fountain & Club \\
\hline Peachy5 & Leslie & Feb 3 & 4:54:22 p.m. & Beach & Home \\
\hline funster & Paul & Feb 8 & 3:58:41 p.m. & Checkers & Club \\
\hline Lucky7 & Marissa & Feb 16 & 3:59:54 p.m. & Main Page & Club \\
\hline violet5 & Ulani & Feb 16 & 4:08:03 p.m. & Main Page & Club \\
\hline $\begin{array}{l}\text { BluSwirls93 } \\
\text { bloofer }\end{array}$ & $\begin{array}{l}\text { Molly } \\
\text { Paige }\end{array}$ & Mar 3 & $\begin{array}{l}\text { 3:50:35 p.m. } \\
\text { never teleported }\end{array}$ & Beach & Club \\
\hline
\end{tabular}

first teleports for the club members was an essential beginning step in tracing individual trajectories of learning this insider practice.

Trajectories of individuals' learning across spaces

In order to pursue how club members learned to teleport and how the practice of teleporting spread among the club, we traced each club member's trajectory of learning to teleport. Starting with the time points of "first teleports" described above, we built descriptions of how the tweens learned, drawing on more qualitative yet focused analysis of the tracking data, videos, and field notes. Then we checked our understanding against interview data to avoid overinterpretation of either data source (see Bruckman 2006). Below, we describe learning trajectories of three club members to illustrate how they traveled across space, time, and people in learning to teleport. In doing so, we also exemplify the ways that we integrated different data to form as complete a picture as possible with the individual as a focal point.

\section{Briana and Gabe: From Whyville to class to club}

While the time point on Table 1 shows Briana's first teleport taking place at 1:29 p.m. on Friday, January 7, during class, her first mention of anything related to teleporting took place at home on Whyville the night before at 8:48 p.m. She had been on Whyville earlier that day in the late afternoon for just 5 min and had logged back in at 8:36 p.m. After stopping briefly by a few places on Whyville, she entered the Greek Theater and immediately started attempting to go to the moon. Unsuccessful because she neither used the right words or syntax ("go to moon" or "travel to the moon"), though she seemed to 
have a grasp of the idea of typing a command to get to the moon, she gave up within a minute and went to the most populated place on Whyville where she twice asked if anyone knew how to get to the moon, which was apparently unsuccessful as well because she again typed an incorrect command to go to the moon, "go to moon." Below we show a simplified transcript of the logfiles, noting time, change of Whyville place, and chat content.

\begin{tabular}{|c|c|c|c|}
\hline 8:48 p.m. & $\begin{array}{l}\text { whskr29 } \\
\text { whskr29 }\end{array}$ & $\begin{array}{l}\text { Greek Theater } \\
\text { Greek Theater }\end{array}$ & $\begin{array}{l}\text { go to moon } \\
\text { travel to the moon }\end{array}$ \\
\hline 8:49 p.m. & whskr29 & Beach & does anybody know how to get to the moon? \\
\hline 8:51 p.m. & whskr29 & Beach & does anyone know how to get to the moon? \\
\hline 8:52 p.m. & whskr29 & Sector Y & go to moon \\
\hline
\end{tabular}

Interestingly, while Whyville activities started in the club the week of January 6, Briana was not with any school friends on Whyville while she was logged in that evening. Most of her understanding of teleporting thus far was from observation of others' conversation about the moon, directly asking others how to get there, and perhaps receiving a response from some willing Whyvillian that was not sufficient for her to teleport. This was not the case on the following day.

On Friday, January 7, at 1:29 p.m., Briana teleported for the first time, notably during class. In order to see the larger context of her first teleport, we zoomed out on the logfiles to include not only her data but also all of the data from any of the school participants (class and club). Unfortunately, video and field note data were not available for this day, but we can still get a good idea of what happened. Notably, at least six other class members in different locations on Whyville (e.g., the Beach, Sector Y, LeilaPatio, Bazaar) all started to attempt to teleport to the moon within 4 min of each other. None of them asked for help in chat, so it is quite likely that one or more class members were describing the process in the shared space of the classroom. Briana herself logged in, went to Whyville Square and typed "teleport to moon" then "teleport moon" within 1 min. Thus, in a lively social context with several other classmates who learned to teleport at the same time, Briana took up the word "teleport" and then correctly teleported. But did she learn to teleport, even though she typed it correctly and started chatting with a school friend on the moon?

Later that evening, Briana logged in again to Whyville and saw a school classmate (not a club member), Gweneth (flamingo55), at the Beach. After talking briefly about a school assignment, Gweneth suggested going to a less crowded place, namely, the moon. Briana tried to teleport but made a typical mistake by inserting the word "to" as in "teleport to moon,"as she had done earlier that day. This mistake would be visible in chat and Gweneth reconfirmed that Briana wanted to go to the moon and asked, "u know how right?" Then she corrected Briana's mistake and told her "u say teleport moon." After this "immediate intervention" (Ching and Kafai 2008), which was politely negotiated between the two classmates, Briana successfully teleported with Gweneth right behind her, and both happened to see other classmates at the moon. Below is the logfile transcript of this evening meeting between classmates.

\begin{tabular}{llll}
\hline $5: 07$ p.m. & $\begin{array}{l}\text { whskr29 } \\
\text { flamingo55 } \\
\text { whskr29 }\end{array}$ & $\begin{array}{l}\text { Beach } \\
\text { Beach } \\
\text { Beach }\end{array}$ & $\begin{array}{l}\text { hey what's up } \\
\text { u dont have your blue paper? } \\
\text { not with me }\end{array}$ \\
$\ldots$ & & $\ldots$ \\
$5: 09$ p.m. & flamingo55 & Beach & do u wanna go somewhere else? \\
& flamingo55 & Beach & its crowded \\
whskr29 & Beach & lets go \\
& flamingo55 & Beach & moon?
\end{tabular}




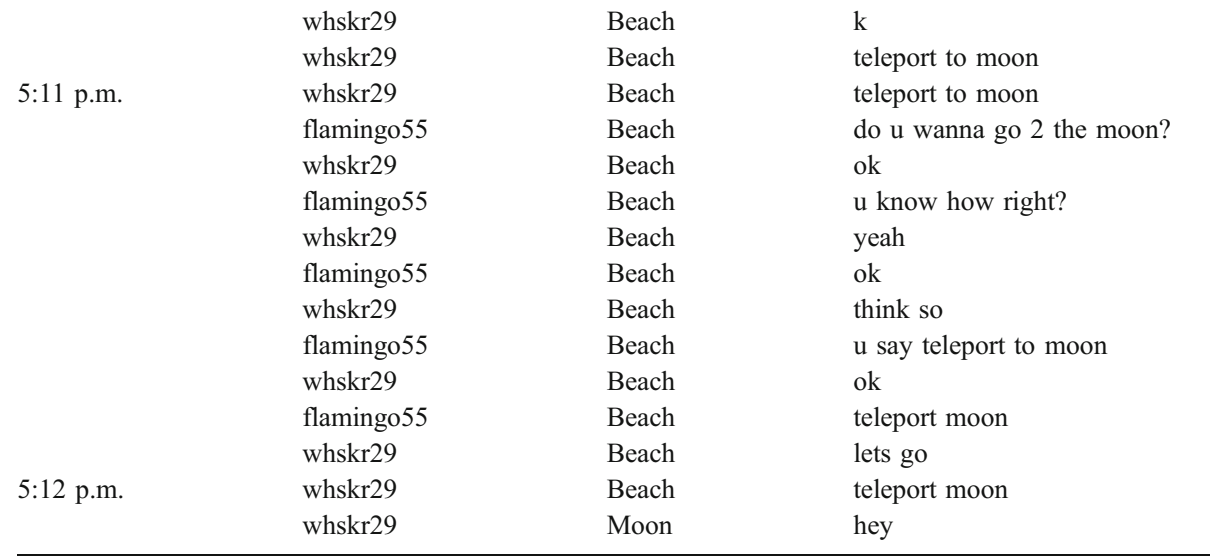

Already we can see that Briana traversed several social spaces in learning to teleport. First, she was among Whyvillians (not known to her outside of Whyville) where she encountered the knowledge that the moon existed on Whyville and that there was a command one could type to get there. In this case, Briana used observation, or what might be called "intent participation" (Rogoff et al. 2003), with the expectation of participating in a social practice discussed among Whyvillians and followed that with direct questioning to an anonymous crowd. In class the next day, a number of students in the same class started to teleport, and Briana teleported for the first time. The situation was probably similar to classrooms where movement and talking loudly across the room is sometimes encouraged, such as those described by Roth (1996) and Windschitl (2001). Finally, later in the evening she met up with a friend from her class on Whyville who retaught her the correct way to teleport, a situation where the just-in-time intervention of a peer observing her syntax mistake helped her to get to a desired social destination.

If we continue this story a little while longer, we will see yet another space of learning and teaching the practice of teleporting. So far, we have only shown how a more qualitative delving into the tracking data allowed us to trace the spread of the practice of teleporting in regard to one club member, taking into account other school members' logfiles. In the next example, we show how video data helped to illuminate how the practice of teleporting began to diffuse among club members.

Gabe (WOW4) was in sixth grade like Briana but not in the same classroom. He, too, appeared to have been introduced to the idea of teleporting about the same time as Briana on the evening of January 6, but was in Whyville with school friends rather than just with Whyvillians at large. He teleported for the first time on January 10 during class, but like Briana knowing how to teleport did not stick. On Wednesday, January 12, during the club, Briana and Gabe were playing on Whyville at adjacent computers. While Gabe was at the Beach, a classmate (Marv, dudeman93) who was not at the club logged into Whyville and said hello to him using Gabe's last name, "hey smith." Gabe called over to Briana to ask who it was that had said hello to him. She identified the Whyvillian as their friend, Marv, who then told Gabe, "go to the moon." Seeing the chat on Gabe's computer, Briana also told Gabe, "Teleport to the moon!" with some excitement in her voice. When Gabe declared that he did not know how, Briana coached him, noticing that he was typing in the same syntax mistake she had made the week before and telling him, "Don't write 'to' just write 'teleport moon,' m-o-o-n." Gabe successfully teleported to the moon, as did Marv several seconds later, and in a couple minutes, Briana joined the two on the moon, 
having gone back to her computer. To put together the larger context of this peer-to-peer teaching and learning of teleporting, we had to juxtapose the video and logfile transcripts (See Table 2).

The above incident shows the first spread of the practice of teleporting in the afterschool club, though obviously the whole incident had a history across the spaces of Whyville and the class. Even in this single meeting of Gabe, Briana, and Marv, we see overlapping social spaces. Marv, apparently logged on at home, saw Gabe on Whyville while Gabe himself was not only on Whyville but also in the club next to Briana-who may have never told Gabe how to teleport if Marv had not come on the scene and suggested going to the Moon. The overlapping and intersecting social spaces of the sixth- grade class, club, and Whyville's thousands of members all played a part in Gabe's learning. This case also shows a common type of collaborative play in the club where one member would hang over the shoulders of another to look at the computer screen-demonstrating some of the openness of the tools (computer screens) and space of the club (Hutchins 1995). It is an

Table 2 Briana coaches Gabe to teleport

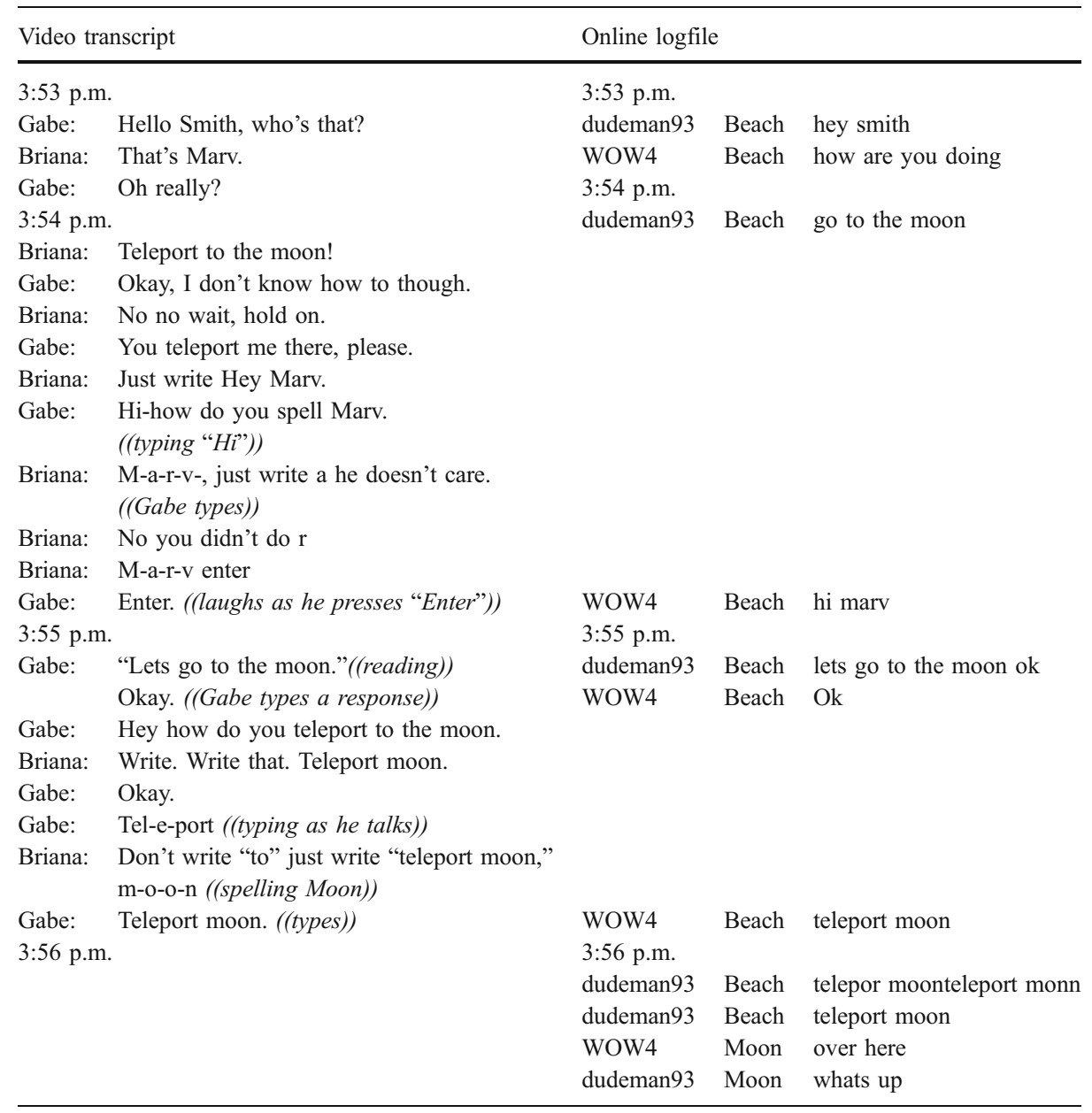


example of the "periodic monitoring" found in groups of mixed expertise by Ching and Kafai (2008), though in our study there were no assigned groups or explicit instructional goals.

It would not have been possible to reconstruct and "trace" Gabe's learning without video data from the club. The logfiles, while illuminating and helpful, were not sufficient on their own. Then again, without the logfiles we would have lost the history of Gabe and Briana's learning trajectories and the whole incident would have seemed like a very simple experience of one club member telling another how to teleport. Below, we show one final example of an individual trajectory of learning where field notes had to be used in conjunction with video and logfiles to put the picture into focus.

\section{Isabel: From club to Whyville}

Briana's first exposure to the idea of teleporting appears to have come from interactions with the Whyville community at large. In contrast, Gabe's first attempts took place during class while among friends who were also teleporting. Isabel, a fourth-grade club participant (9-years old) provides yet another initial context for the start of a trajectory to learning the insider practice of teleporting, this time in the after-school club. From Table 1, we can see that Isabel first teleported on Monday, January 31, while in the club. Or did she? When we took into account the combined field notes, video, and logfiles surrounding the time of her teleporting, we came to a different conclusion.

About midway through the club on January 31, Cole and Isabel were at a computer in a side room where Isabel (ivy06) was logged on. To Isabel, Cole (leo95) described one of his girlfriends on Whyville and pulled up a picture of her from City Records (which serves as a yearbook of sorts with pictures and descriptions of all Whyvillians). While this was happening, one of the other boys (Blake) in the club yelled to Cole from the main room to meet him at the moon. Cole yelled, "Hang on!" but was not himself logged into Whyville. Rather, the command to teleport appeared on Isabel's logfile (see Table 3). Coincidentally, the girl Cole had just pointed out to Isabel was on the moon, and Isabel wrote a quick comment to her. Soon after this, it was time to switch who was logged on to Whyville, and Cole asked Isabel to log off. So while Isabel's first teleport was recorded on January 31, and

Table 3 The larger context of Isabel's first teleport

\begin{tabular}{lcc}
\hline Field notes & Video data & Online logfile \\
\hline $\begin{array}{l}\text { Cole visited with Isabel, telling } \\
\text { her about a girl who sent him a }\end{array}$ & $\begin{array}{c}\text { Blake: Cole! Meet } \\
\text { me at the Moon! }\end{array}$ \\
$\begin{array}{l}\text { ymail. He typed the girl's username } \\
\text { on Isabel's computer so she could }\end{array}$ & & \\
$\begin{array}{l}\text { what the girl looked like. } \\
\sim 4: 00 \text { pm }\end{array}$ & Cole: Hang on! ((far away)) & $4: 01$ p.m. \\
Cole asked Isabel to log off so he & ivy06 teleport moon \\
could use the computer & teleport moon \\
& & $4: 02$ p.m. \\
& ivy06 leo95 says \\
\end{tabular}


while she was certainly present while it happened, she probably did not type it in, or if she did, it was dictated by Cole.

Isabel's online activities over the next day show that at the very least she (like Briana and Gabe) did not actually remember how to teleport (or even to use the word "teleport") on her next attempts. The following day, she made a number of attempts to teleport (the first one was even correct after coaching from a Whyvillian):

\begin{tabular}{|c|c|c|c|}
\hline \multirow[t]{2}{*}{ 3:13 p.m. } & ivy06 & Beach & go to moon \\
\hline & ivy06 & Beach & do $u$ know how to go to the moon? \\
\hline \multirow[t]{2}{*}{ 3:14 p.m. } & ivy06 & Beach & how? \\
\hline & ivy06 & Beach & teleport mars \\
\hline 3:15 p.m. & ivy06 & Mars & teleport moon \\
\hline 3:16 p.m. & ivy06 & Mars & teleport moon \\
\hline \multicolumn{4}{|l|}{$\ldots$} \\
\hline 3:17 p.m. & ivy06 & Beach & no how to go to the moon \\
\hline 3:24 p.m. & ivy06 & Beach & how do u go to the moon? \\
\hline
\end{tabular}

Finally, after asking a few more people at the Beach, Isabel finally seemed to learn how to teleport for good because she stopped misspelling teleport as "teleoport" and successfully transported back and forth to various solar system spots in Whyville.

In the examples above, we have tried to demonstrate the complexity of individuals' pathways to teleporting and how some of the knowledge sharing among club members happened. There were only three club members who learned to teleport in a single type of social space: Zoe and Caitlin learned in Whyville from people unassociated with the school, and Kyle learned in the sixth-grade classroom in verbal communication with friends. All of the others moved across spaces in some way to learn how to teleport, as the examples of Briana, Gabe, and Isabel demonstrate. In describing their cases, we have begun to provide a close-up picture of knowledge-sharing instances between club members, class members, and Whyvillians - both in the club (between Briana and Gabe and in the complex interaction between Isabel, Cole, and Blake) and in Whyville (between Briana and her classmate, and in Briana and Isabel's direct questioning of Whyvillians at large). Below, we zoom out even further in our analysis to look across the club as a whole to how the practice of teleporting spread, looking particularly at patterns of teaching online and at a club-wide event.

The diffusion of teleporting across the club: Patterns and events

In our discussion of the knowledge sharing and diffusion of teleporting so far, we have looked at minute instances of the first time each tween teleported, and the pathways or trajectories of individuals in how they learned to teleport. Each of these hints at the need to understand some of the larger social contexts that serve as backgrounds for these events. So let us zoom out our lens of analysis to begin to account for the more widespread social interactions that influenced the spread of teleporting among club members. As we do so, we shift from tracing an individual's learning backward and forward from a specific time point to more traditional thematic analysis of events and interactions between tweens in the club and in the broader context of Whyville.

The after-school club began as a quiet environment. Members played in partners on clusters of computers and occasionally asked the researcher present for help. Gradually, the members moved from individual play to more collaborative meetings in various places on Whyville. As the tweens' participation in Whyville shifted to be more social, so did their 
club interactions. Instead of quietly playing a game by oneself or shopping for face parts with a friend sitting nearby, cross-club interactions became more frequent: running between computers, high-fiving someone for a good mudball throw, and shouting across the room to "Go to the Mall!" or "Meet me at the Moon!" These types of cross-space social interactions really took hold during the fourth and fifth weeks of the club, between January 24 and February 4. So it is not a surprise that almost half of the club teleported for the first time during those weeks (see Table 1). Like Isabel, who became interested in teleporting when Blake and Cole were organizing a get-together on the Moon, many other members were also influenced in the context of the newly buzzing social life of the club.

This social buzz provided opportunities for news of the Moon or other planets to spread. As tweens called across the room, others inevitably became curious about the Moon and inquired about how to get there - either in the club or Whyville (or with club members or classmates on Whyville). But these were always gatherings of a few individuals, and not all club members took up the practice of teleporting at this time. This may be because teleporting is not an explicit task or goal to accomplish on Whyville, unlike most of the other research on knowledge sharing and diffusion where a shared task underlies sharing of techniques (e.g., Roth 1996) or argument stratagems (e.g., Anderson et al. 2001). Yet one major club-wide incident changed the interactions in the club, affecting who knew how to teleport and where most members teleported.

\section{The "incident": A club-wide event}

On February 16, a club-wide incident occurred that introduced a particular planetary location to many club members and changed the social interactions in the club as a whole. It began with Leslie, who the day before had learned about Saturn through a common pattern of experimentation with places to teleport. Once she figured out that she could teleport to the Moon, she, as many club members before her, tried to teleport to a number of locationssome of which existed on Whyville and others that did not. Mars, Earth, Jupiter, and Saturn are teleport locations while other planets such as Venus, Mercury, and Pluto are not. Leslie rattled off a string of teleport commands to these locations and, thus, discovered Saturn (e.g., "teleport moon, teleport mars, teleport venus, teleport earth, teleport pluto, teleport saturn").

On the 16th, Leslie sent a ymail to three girls in the club to come and meet her at Saturn. This invitation seems to have provided the instigation for Marissa and Ulani to teleport for the first time, and while Isabel knew how to teleport to the Moon, Mars, and Earth, she had not been to Saturn before that day. While at Saturn, a Whyvillian not a part of the club, insulted Ulani, who yelled out to the club that someone had said something rude to her on Saturn. Immediately, several other club members teleported to Saturn, two for the first time (they had to ask how to spell it), and threw projectiles at the offender. By the end of the day, almost all of the club members had been to Saturn. Further, the daily average of Saturn visits by club members doubled for the following 2 weeks.

While it is true that Marissa, Ulani, and Isabel teleported to Saturn for the first time as a direct result of Leslie's invitation, that does not account for the spike in Saturn visits across club members - for 2 weeks. This seems to go beyond knowledge diffusion to a change in the practice of teleporting across club members. For 2 weeks, Saturn was a regular location to teleport among the entire club. So not only did club members learn about the location of Saturn, they incorporated it into their already existing teleporting practice with great frequency. Other interactions among club members also changed in ways that go beyond the scope of this paper. Suffice it to say that shared play moved from between-boys and betweengirls to be more cross-gender for the duration of the club (see Fields and Kafai 2008). 
So far in the findings, we have moved from specific time points of teleporting and seeing that almost all club members eventually learned to teleport, to the ways that individuals traversed social spaces in learning to teleport and looking at some knowledge sharing between individuals, to trends in the club that facilitated the spread of the practice of teleporting and a club-wide string of events that changed the practice of teleporting in the club. There is one last finding that we want to report here, regarding the diffusion of the practice of teleporting on Whyville. Earlier, we described how Briana and Isabel solicited help from randomly encountered Whyvillians on how to get to the moon. This was one of the common strategies club members employed in their efforts to figure out how to teleport (once they discovered that the Moon existed). Yet there is evidence of other kinds of interactions on Whyville and among Whyvillians at large regarding knowledge diffusion.

\section{Peer pedagogy conversations in Whyville}

When we look at all of the online conversations of school participants on Whyville where teleporting was mentioned (47 in all), we find some interesting trends. First, 91\% of any conversation where the word "teleport" was used by a school member involved teaching about teleporting in some way-either helping someone teleport for the first time or informing someone of other places to teleport. In other words, teaching someone about teleporting was a common practice of school members while present in Whyville. Second, about half of these exchanges were between school members and about half were between a school member and an unknown Whyvillian. This means that they taught each other about teleporting while together on Whyville (as Gweneth did for Briana) and that they also taught other kids in Whyville. The diffusion of the practice to Whyvillians at large may have been responses to questions written at large in a populous social space like the Beach or in the context of creating a social gathering. In fact, $62 \%$ of all the teleporting chats were in the context of creating an intimate get-together (like Gweneth suggesting that she and Briana go to the Moon) or a giant social gathering (e.g., "PARTY AT THE MOON!"), the latter being much less common than the former. Finally, almost all of the dialogues $(93 \%)$ took place outside of school time. This finding means that when school members were teaching each other to teleport on Whyville, it was not at times when they were physically together in class or the club. This confirms a preference expressed in interviews to learn about Whyville by talking to friends present in the club over asking people on Whyville. It seems to be much easier to shout, "How do I...?" to friends physically present than to type it in chat. Still, the frequency of the conversations in Whyville demonstrates that school members took advantage of the opportunities to learn from each other outside of class and club space.

\section{Discussion}

In this discussion, we wish to address what our study has contributed to understanding the complexities of peer-to-peer learning in unstructured, informal contexts; methodological challenges and limitations of our research; and considerations for designing situations that capitalize on multiple shared spaces.

Knowledge sharing and diffusion in informal, unstructured environments

In this study of knowledge sharing and diffusion of a specific gaming practice across virtual and physical settings, we found that the tween club members marshaled a number of 
resources and strategies, many already found in studies of intergroup collaboration in learning-by-design classrooms. However, none of these strategies was "between groups" as in the prior studies of knowledge diffusion. Rather, the sharing and diffusion of the practice of teleporting took place within an amorphous group of tweens loosely defined by the common (if tacit) goal of participating in Whyville that included not only the club but also some classrooms and Whyvillians at large. In contrast to previous studies, we traced the detailed spread of a specific practice across almost all participants of the club, something data from most studies do not afford. From this, we were able to document not only the knowledge sharing that took place but also individual application and experimentation (such as trying out different commands to get to the Moon or experimenting with planetary locations) that played a significant role in the adoption of teleporting.

Certainly, there are common features with some of the classrooms described in earlier studies, such as open spaces where shouting or moving across the room was acceptable as well as observing, specific questioning, interacting in public spaces (see Windschitl 2001), and even monitoring and intervening more commonly found within small groups (Ching and Kafai 2008). There are also some notable absences in the settings visited by club members compared with the students in the more commonly studied design classrooms. For instance, in design classrooms, much has been made about shared artifacts, objects that are viewable and collaboratively created (Ching and Kafai 2008; Roth 1996; Windschitl 2001). But with regard to teleporting, the only visible artifacts are fleeting moments of typed chat about teleport locations such as the Moon or a typed command solely visible on the screen of the person trying to teleport. Thus, many of the strategies listed in studies where common artifacts are designed, such as analyzing drawings or discussing physical materials, were not available in the case of learning the practice of teleporting. There was also no knowledgeable teacher to facilitate groups' learning or instructional guides that tweens referenced (Barab et al. 2001). Club members relied on "overheard" conversations (visible or audible) or invitations to social activities in which teleporting played a part to start their often multiday efforts to learn to teleport. In this way, the knowledge sharing was similar to peer learning in massively multiplayer online games for older audiences such as the World of Warcraft, which Nardi et al. (2007) described as "erratic, spontaneous, contextual and driven by small events."

Further, multiple spaces were available to club members beyond the traditional physically bounded classroom space. The tweens could be in the club, one of many spaces in Whyville, the sixth-grade classrooms, and, of course, home where there were potentially many other influences outside the range of our data collection (e.g., siblings, Instant Messaging, phone calls). Our study demonstrates that most of the club members used the multiple social spaces available to them to learn how to teleport. This included meeting friends from school in Whyville, confirming that "virtual" does not necessarily mean unrelated to "physical" social settings. One implication for this is that virtual spaces can expand the opportunities for peer-to-peer learning and that where virtual spaces are introduced, studies of learning should encompass multiple spaces of collaboration-not bifurcating the physical from the virtual. This follows with Lindtner et al.'s (2008) findings that players in Internet cafés in China established and interrelated meaningful connections between people and resources in the virtual worlds and Internet cafes, societal norms, and in-game goals. It also supports Stevens et al.'s (2008) findings that game play at home involved the marshaling of multiple resources, including people and game guides (physical and virtual). This opens up a conversation to debate whether knowledge diffusion in classroom spaces is bound to a specific room and time. What about other areas where students can discuss classroom activities, such as at recess, lunch, or through extensions of 
school relationships at home? The findings from this study suggest that we need to cast nets beyond classrooms in capturing and understanding collaborative learning.

\section{Methodological challenges and limitations}

Our use of connective ethnography responded to growing concerns to understand participants' learning across multiple spaces. Our analyses clearly demonstrated that a focus solely on the after-school club space and on any one data source would have limited our understanding of when and how players came to learn about teleporting. One contribution provided by our study is to showcase how the integration or connection of multiple data sources in our analysis allowed for a thicker description, to use Geertz's term (1973), of how young players learned a particular practice in a virtual world. It is, of course, possible to add further layers of interpretation by examining the social networks that emerged over time in the after-school club. For instance, previous research by Taylor (2006) and Ducheneaut et al. (2006) illustrated the emergence and importance of such social networks in online communities of players. We think these are promising avenues to pursue in further research.

A further contribution is our approach to analyzing click-level data beyond the traditional quantitative summaries of pages viewed or sites visited. Arguably, we conducted an ethnographic analysis of a practice, observing the practice as well as individuals through direct and indirect means. Our strategic choice of focusing on a practice rather than individuals (though we did some of that, too, as it pertained to the practice of teleporting) allowed us to leverage the record-keeping facility of logfiles to focus our multimodal analysis on particular time points. In further analyses, we are using the logfiles to reconstruct participation portraits of individual Whyville players revealing their trajectories of participation and often hidden activities - hidden because they were neither captured in our field notes, or video recordings, or reported in interviews (see Fields and Kafai, forthcoming, The hidden life on an avatar: Identities-in-practice of a girl player in a digital world. In: C. C. Ching \& B. Foley (Eds.), Constructing identity in online worlds. New York, NY: Cambridge University Press). However, we are also aware that even adding more data sources will not solve a fundamental conundrum of all research - to account as fully as possible about events and player practices in communities. Our accounts are not complete as our videos, and logfiles are not fully representative of all interactions. Videos only documented activities of tweens at two clusters of computers each day. Further, because only consenting players' logfiles and chat were recorded and available for our analysis, reading the logs is often like listening to a one-sided telephone conversation. We were able to reassemble many conversations and events because consenting after-school club and sixth-grade students adopted Whyville for their own meeting purposes outside of school and club time. Yet, even these were challenging to reassemble because accounts logged in chronological sequence do not capture concurrent interactions in multiple spaces. Perhaps future researchers will find better ways to capture and organize logfile collection in massively populated virtual worlds.

\section{Considerations for design}

As educators move forward to design educational applications for virtual worlds, the findings from our research suggest the following. First, in the clamor to create virtual spaces of collaboration, there is a need to focus on offline spaces and interactions as well. Design studies tend to focus on the interface of the digital/online world whereas our study suggests that concurrent offline interactions can change the nature of learning. For instance, 
players capitalized on the presence of others in the club to ask for help out loud rather than through chat. For younger populations who are not always allowed in Internet cafés (see Lin 2008) or in places such as the United States, where such locales are often nonexistent, libraries may be new areas for peer knowledge sharing in regard to informal virtual worlds or other digital tools (Phaire et al. 2008). Thus, it might be worthwhile to "build-in" scaffolds that ask for participation outside of the virtual world or computer screen.

Second, the idea of making practices "secret" might strike educational designers as counterintuitive but our observations seem to indicate that players in virtual worlds see a certain value in discovering hidden practices; they see it as a form of membership. Learning about teleporting was much more than the act of navigating from one space to the next; it meant joining others and displaying cultural knowledge. This phenomenon is similar to the practices surrounding the collaborative development of cheats or cheat sites that act to facilitate knowledge sharing (Fields and Kafai 2007; Engeström 2008). It remains to be seen though, how feasible such an approach may be to more complex activities. We realize that the access to the practice of teleporting was relatively easy (though more complex than we would have predicted for a two-word command) because of how many people (in Whyville and among school peers) knew it and were available to share it. The access for club members may have been increased because of the shared club space available to them, at least compared to tweens who accessed Whyville solely from home.

\section{Conclusion}

In this paper, we illustrated the ways that tweens shared and diffused an insider gaming practice across an after-school club, classrooms, and the virtual world of Whyville. In the primarily unstructured, informal settings, the tweens used a number of practices such as observation, direct questioning, monitoring, and intervening already identified in studies of knowledge sharing in classrooms with structured small groups collaborating on designs. However, they used these natively, without explicit instructional goals, guides (human or textual), or collaborative design projects, and supplemented their peer-to-peer learning with individual experimentation. Further, most tweens traversed multiple social spaces in their learning to teleport, including not only the club but also school friends on Whyville and Whyvillians at large, though they expressed a preference for getting help in the context of the club. They also contributed to the spread of teleporting on Whyville itself through their social interactions and conversations with Whyvillians.

We also demonstrated how data analyses that include multiple sources and spaces of learning helped us to avoid the dichotomy between online/offline and in/out of school interactions that has dominated research studies. Our approach to connective ethnography helped us to integrate learning in different spaces into a comprehensive account of one single practice and document the diffusion of that practice in an informal, unstructured group of tweens. We see future studies either analyzing individual trajectories of participation and gaining access to previously "hidden lives" of avatars (Fields \& Kafai, forthcoming) or studying the spread of more complex practices with more social nuance than teleporting (Fields and Kafai 2008). We also see future directions in studying physical contexts of informal collaborative learning in game play such as libraries or Internet cafés (e.g., Lindtner et al. 2008) taking into account social interactions in virtual spaces unlike prior studies of Internet cafés. Perhaps scholars will eventually use methods developed to study people across virtual spaces to understand their learning across multiple physical spaces (Leander and McKim 2003), representing a "return to the physical." 
Acknowledgments The writing of this paper was supported by a grant of the National Science Foundation (NSF-0411814) to the second author. The views expressed are those of the authors and do not necessarily represent the views of NSF or the University of California. We wish to thank Linda Kao for documenting club activities in field notes and Tina Tom for help logging the video data. Many thanks also to Melissa Cook, Maria Quintero, Michael Giang, David Feldon, and the LTRG research group at UCLA for comments on earlier drafts of this paper.

\section{References}

Anderson, R. C., Nguyen-Jahiel, K., McNurlen, B., Archodidou, A., Kim, S.-Y., Reznitskaya, A., et al. (2001). The snowball phenomenon: spread of ways of talking and ways of thinking across groups of children. Cognition and Instruction, 19(1), 1-46.

Barab, S. A., Hay, K. E., Barnett, M., \& Squire, K. (2001). Constructing virtual worlds: Tracing the historical development of learner practices. Cognition and Instruction, 19(1), 47-94.

Barab, S. A., Thomas, M., Dodge, T., Carteaux, R., \& Tuzun, H. (2005). Making learning fun: Quest Atlantis, a game without guns. Educational Technology Research and Development, 53(1), 86-107.

Bainbridge, W. S. (2007). The scientific research potential of virtual worlds. Science, 317(5837), 472-476.

Barnes, B. (2007). Disney acquires web site for children. New York Times. Retrieved August 2, 2007, from http://www.nytimes.com. August 2.

Beavis, C., Nixon, H., \& Atkinson, S. (2005). LAN cafes: Cafes, places of gathering, or sites if informal teaching and learning? Education, Communication, Information, 5(1), 41-60.

Brown, A., \& Campione, J. (1994). Guided discovery in a community of learners. In K. McGilly (Ed.), Classroom lessons: Integrating cognitive theory and classroom practice (pp. 229-290). Cambridge, MA: MIT.

Bruckman, A. (2000). Situated support for learning: storm's weekend with Rachael. The Journal of the Learning Sciences, 9(3), 329-372.

Bruckman, A. (2006). Analysis of log file data to understand behavior and learning in an online community. In J. Weiss, J. Nolan, J. Hunsinger, \& P. Trifonas (Eds.), The International handbook of virtual learning environments (pp. 1449-1465). Netherlands: Springer.

Charmaz, K. (2000). Grounded theory: objectivist and constructivist methods. In N. K. Denzin, \& Y. S. Lincoln (Eds.), Handbook of qualitative research (pp. 509-535). Thousand Oaks, CA: Sage.

Ching, C. C., \& Kafai, Y. B. (2008). Peer pedagogy: student collaboration and reflection in a learning through design project. Teachers College Press. Retrieved June 17, 2008, from http://tcrecord.org.

Clarke, J., \& Dede, C. (2007). MUVEs as a powerful means to study situated learning. In C. Chinn, G. Erkins, \& S. Puntambekar (Eds.), The proceedings of CSCL 2007: Of mice, minds and society. New Brunswick, NJ, USA.

Cohen, E. G., \& Lotan, R. A. (1995). Producing equal-status interaction in the heterogeneous classroom. American Educational Research Journal, 32(1), 99-120.

Dede, C., Nelson, B., Ketelhut, D. J., Clarke, J., \& Bowman, C. (2004). Design-based research strategies for studying situated learning in a multi-user virtual environment. In Y. B. Kafai, W. A. Sandoval, N. Enyedy, A. S. Nixon, \& F. Herrera (Eds.), Proceedings of the sixth international conference of the learning sciences. Mahwah, NJ: Lawrence Erlbaum Associates.

Ducheneaut, N., Yee, N., Nickell, E., \& Moore, R. (2006). Building an MMO with mass appeal: a look at gameplay in World of Warcraft. Games and Culture, 1, 281-317.

Engeström, Y. (2008). From design experiments to formative interventions. In V. Jonker, A. Lazonder, \& C. Hoadley (Eds.), Proceedings of the eighth international conference of the learning sciences. Utrecht, Netherlands: University of Utrecht.

Fields, D. A., \& Kafai, Y. B. (2007). Stealing from Grandma or generating knowledge: Contestations and effects of cheats in a tween virtual world. In A. Baba (Ed.), Situated play: Proceedings of the third international conference of the digital games research association (DiGRA) (pp. 194-202). Tokyo, Japan: The University of Tokyo.

Fields, D. A., \& Kafai, Y. B. (2008). Knowing and throwing mudballs, hearts, pies, and flowers: A connective ethnography of gaming practices. In V. Jonker, A. Lazonder, \& C. Hoadley (Eds.), Proceedings of the eighth international conference of the learning sciences. Utrecht, Netherlands: University of Utrecht.

Gee, J. P. (2003). What video games have to teach us about learning and literacy. New York, NY: Palgrave Macmillan.

Geertz, C. (1973). The interpretation of cultures: Selected essays. New York: Basic Books.

Glaser, B. G., \& Strauss, A. L. (1967). The discovery of grounded theory. Chicago: Aldine.

Goodwin, M. H. (2006). Hidden lives of girls: Games of stance, status and exclusion. Oxford: Blackwell.

Hine, C. (2000). Virtual ethnography. London: Sage.

Hutchins, E. (1995). Cognition in the wild. Cambridge, MA: MIT. 
Jansz, J., \& Martens, L. (2005). Gaming at a LAN event: The social context of playing video games. New Media \& Society, 7(3), 333-355.

Jones, R. (2004). The problem of context in computer mediated communication. In P. LeVine, \& R. Scollon (Eds.), Discourse and technology: Multimodal discourse analysis (pp. 20-23). Washington D. C.: Georgetown University Press.

Kafai, Y. B. (2008). Gender play in a tween gaming club. In Y. B. Kafai, C. Heeter, J. Denner, \& J. Sun (Eds.), Beyond Barbie and Mortal Kombat (pp. 111-124). Cambridge, MA: MIT.

Kafai, Y. B., Feldon, D., Fields, D. A., Giang, M., \& Quintero, M. (2007). Life in the time of Whypox: A virtual epidemic as a community event. In C. Steinfield, B. Pentland, M. Ackerman, \& N. Contractor (Eds.), Communities and technologies 2007 (pp. 171-190). New York: Springer.

Kafai, Y. B., \& Giang, M. (2008). Virtual playgrounds. In T. Willoughby, \& E. Wood (Eds.), Children's learning in a digital world (pp. 196-217). Oxford: Blackwell.

Kim, I.-H., Anderson, R. C., Nguyen-Jahiel, K., \& Archodidou, A. (2007). Discourse patterns during children's collaborative online discussions. The Journal of the Learning Sciences, 16(3), 333-370.

Lam, W. S. E. (2000). Second language literacy and the design of the self: a case study of a teenager writing on the Internet. TESOL Quarterly, 34(3), 457-483.

Lam, W. S. E. (2004). Border discourses and identities in transnational youth culture. In J. Mahiri (Ed.), What they don't learn in school: Literacy in the lives of urban youth (pp. 79-97). New York: Peter Lang.

Latour, B. (2005). Reassembling the social: An introduction to Actor-Network-Theory. Clarendon: Oxford University Press.

Lægran, A. S., \& Stewart, J. (2003). Nerdy, trendy or healthy? Configuring the Internet café. New Media \& Society, 5(3), 357-377.

Lave, J., \& Wenger, E. (1991). Situated learning and legitimate peripheral participation. Cambridge: Cambridge University Press.

Leander, K. M. (2008). Toward a connective ethnography of online/offline literacy networks. In D. Leu, J. Cairo, M. Knobel, \& C. Lankshear (Eds.), Handbook of research on new literacies (pp. 33-65). New York: Erlbaum.

Leander, K. M., \& Lovvorn, J. F. (2006). Literacy networks: following the circulation of texts, bodies, and objects in the schooling and online gaming of one youth. Cognition and Instruction, 24(3), 291-340.

Leander, K. M., \& McKim, K. K. (2003). Tracing the everyday 'sitings' of adolescents on the Internet: A strategic adaptation of ethnography across online and offline spaces. Education, Communication, Information, 3(2), 211-240.

Lin, H. (2008). A cultural geography of gaming experiences in homes, cybercafés and dormitories. In Y. B. Kafai, C. Heeter, J. Denner, \& J. Sun (Eds.), Beyond Barbie and Mortal Kombat (pp. 67-82). Cambridge: MIT.

Lindtner, S., Nardi, B., Wang, Y., Mainwaring, S., Jing, H., Liang, W. (2008). A hybrid cultural ecology: World of Warcraft in China. Proceedings of CSCW. San Diego, California.

Nardi, B. A., Ly, S., \& Harris, J. (2007). Learning conversation in World of Warcraft. Proceedings, HICSS.

Phaire, C. B., Cady, D., Hommel, M., Jarrett, K., Robbins, T., \& Chamberlain, B. (2008). Games and learning in practice: An educator panel on implementing curricula. Madison, WI: Symposium presented at the annual conference of Games + Learning + Society 4.0 July.

Rogoff, B., Paradise, R., Arauz, R. M., Correa-Chavez, M., \& Angelillo, C. (2003). Firsthand learning through intent participation. Annual Review of Psychology, 54, 175-203.

Roth, W.-M. (1996). Knowledge diffusion in a grade 4-5 classroom during a unit on civil engineering: An analysis of a classroom community in terms of its changing resources and practices. Cognition and Instruction, 4(2), 179-220.

Steinkuehler, C. A. (2006). Massively multiplayer online video gaming as participation in a discourse. Mind, Culture, and Activity, 13(1), 38-52.

Steinkuehler, C. A., Duncan, S. C., \& Simkins, D. W. (2007). Massively multiplayer online games \& education: An outline of research. In C. Chinn, G. Erkins, \& S. Puntambekar (Eds.), The proceedings of CSCL 2007: Of mice, men and society (pp. 674-684). New Brunswick, NJ, USA.

Stevens, R., Satwicz, T., \& McCarthy, L. (2008). In-game, in-room, in-world: Reconnecting video game play to the rest of kids' lives. In K. Salen (Ed.), Ecology of games: MacArthur foundation series on digital media and learning (pp. 41-66). Cambridge, MA: The MIT.

Swalwell, M. (2003). Multi-player computer gaming: 'Better than playing (PC Games). Reconstruction: Studies in Contemporary Culture 3(4). Retrieved September 1, 2006, from http://reconstruction.eserver. org/034/swalwell.htm.

Taylor, T. L. (2006). Play between worlds. Cambridge: MIT.

Windschitl, M. (2001). The diffusion and appropriation of ideas in the science classroom: Developing a taxonomy of events occurring between groups of learners. Journal of Research in Science Teaching, 38 (1), 17-42. 